\title{
CONDUTIVIDADE HIDRÁULICA DE BARREIRAS DE PROTEÇÃO PRODUZIDAS COM SOLO ARENOSO ESTABILIZADO QUIMICAMENTE
}

\section{HYDRAULIC CONDUCTIVITY IN \\ ENVIRONMENTAL LINERS PRODUCED WITH SANDY SOIL, CHEMICALLY STABILIZED.}

\section{Rizzo, R. P. ${ }^{1}$, Ribeiro, R. A.V. ${ }^{2}$; Lollo, J.A. ${ }^{3}$}

Faculdade de Engenharia de Ilha Solteira - UNESP -Alameda Bahia, 550 Ilha Solteira-SP - CEP:15.385-000

${ }^{1}$ rizzo@dec.feis.unesp.br, ${ }^{2}$ binhobill@,terra.com.br,

3lolloja@dec.feis.unesp.br

\section{RESUMO}

Foi testada a condutividade hidráulica de barreiras de proteção ambiental produzidas com solo arenoso (65\% de areia e $27 \%$ de argila) estabilizado quimicamente com cal e cimento. Foram ensaiados corpos de prova das misturas compactadas usando as técnicas de ensaio de permeabilidade a carga variável e em área plena considerando os fatores tipo de estabilizante, teor de estabilizante, tempo de cura e condição de exposição. Os resultados dos ensaios de permeabilidade mostraram valores de condutividade hidráulica inferiores a $10^{-9} \mathrm{~m} / \mathrm{s}$, portanto compatíveis com a finalidade pretendida. É proposta uma seqüência de procedimentos a ser adotada em situações similares nas quais se pretenda aplicar esta técnica.

Palavras-chave: barreiras de proteção, condutividade hidráulica, solo-cal, solo-cimento, estabilização de solos.

\section{ABSTRACT}

Hydraulic conductivity of barriers produced with sandy soil $(65 \%$ sand and $27 \%$ clay) stabilized with lime and cement was tested. Specimens produced with compacted mixtures and tested using variable charges and total surface tests in order to determine hydraulic conductivity. Some factors vary during the tests, like the kind of aditive (lime and cement), the 
amount of lime and cement, cure time and exposition condition. Obtained hydraulic conductivity values were smaller than $10^{-9} \mathrm{~m} / \mathrm{s}$, showing values fully compatible with the intended purpose. Is also proposed a sistematic procedure to aply this techinque in simmilar situations.

Key words: protection barriers, hydraulic conductivity, soil-whitewash, soil-cement, stabilization.

\section{INTRODUÇÃO}

O potencial de contaminação do subsolo gerado pela disposição de resíduos na natureza, pode ser reduzido com a construção de dispositivos que evitem ou retardem a infiltração de substâncias no subsolo. Tais dispositivos, denominados barreiras de proteção ambiental, podem ser constituídos de materiais naturais, artificiais ou da combinação de ambos.

Para que um material satisfaça os requisitos para atuar como barreiras de proteção ambiental, é necessário que ele apresente baixa condutividade hidráulica e boa capacidade de retenção de íons. Dentre os materiais naturais tal comportamento é apresentado por argilas puras (como bentonita e montmorilonita) ou por solos de textura francamente argilosa, com alta plasticidade de percentagens maiores que $20 \%$ de argilominerais de alta atividade em sua composição.

Em regiões de clima tropical como o Brasil, materiais com tais propriedades não se encontram sempre disponíveis, havendo predominância de solos com texturas arenosa ou média, os quais costumam apresentar altos valores de condutividade hidráulica e baixa capacidade de troca catiônica.

Assim, o uso de argilas puras para a construção de barreiras pode significar maiores custos de execução da obra podendo vir a inviabilizá-la. Buscando uma solução técnica e economicamente viável, foi testado o uso de solo arenoso (mais comum no interior do Estado de São Paulo) compactado estabilizado com cal ou cimento para tal finalidade.

\subsection{CARACTERÍSTRICAS DAS BARREIRAS DE PROTEÇÃO AMBIENTAL}

O termo barreiras de proteção é normalmente utilizado para designar camadas de baixa permeabilidade, constituídas de materiais naturais, artificiais ou da combinação de ambos, que têm por objetivo proteger as vizinhanças da percolação de fluidos. Esses dispositivos são utilizados em 
diversos tipos de obras como canais, reservatórios, diques, lagoas de rejeito, lagoas de tratamento de resíduos e aterros sanitários (LEITE A.L.L., 1997).

Segundo Folkes, (apud LEITE J.C., 2000), a escolha do tipo de barreira é influenciada pelos seguintes fatores: uso a que se destina; o ambiente físico no qual será inserida; material a ser usado na construção; taxa de infiltração; e vida útil do projeto.

Para que um material possa ser utilizado na construção de barreiras de proteção, é necessário que apresente certas características que garantam baixa permeabilidade e boa capacidade de retenção de íons. Para Elsbury (apud LEITE, J.C. 2000), estas características são: textura do solo, capacidade de troca catiônica, $\mathrm{pH}$ e permeabilidade.

A escolha do tipo de solo deve ser feita com base na sua trabalhabilidade, gradação e expansividade. Caso o solo não apresente as características exigidas em projeto ele pode ser submetido a um processo de tratamento que lhe confira as propriedades desejadas.

Tal processo de tratamento é normalmente denominado estabilização do solo. Uma das formas de se promover essa estabilização, é acrescentar ao solo uma certa quantidade de cal ou de cimento compactando-o, surgindo daí os produtos solo-cal e solo-cimento.

Uma outra característica fundamental na escolha do material a ser usado na construção de barreira de proteção é sua baixa permeabilidade, que depende de fatores como a porosidade, tamanho, distribuição, forma e arranjo das partículas do meio.

\subsection{PROCESSOS CONSTRUTIVOS DE BARREIRAS DE PROTEÇÃO}

Por se tratar de um assunto ainda recente no Brasil, não existe atualmente metodologia nacional para a construção de barreiras de proteção. O que há são propostas de adaptação de normas de outros países, levando em consideração as diferenças do clima e dos solos brasileiros. Dentre as normas internacionais, as mais utilizadas no Brasil são a Britânica e a Alemã. A figura 1 mostra o corte transversal de um aterro sanitário segundo a norma alemã.

No Brasil trabalhos têm sido desenvolvidos visando propor alternativas construtivas com o uso de materiais geossintéticos. A Figura 2 ilustra propostas de seção transversal de barreiras segundo a Legislação Federal Brasileira (2a) e a Legislação do Estado de São Paulo (2b). 


\subsection{PROPRIEDADES A SEREM ATENDIDAS}

Para que uma que uma barreira tenha um bom desempenho é necessário que apresente valores de coeficiente de permeabilidade $(\mathrm{k})$ entre $10^{-9}$ e $10^{-10} \mathrm{~m} / \mathrm{s}$ e que sua condutividade hidráulica não aumente quando o mesmo estiver sob a ação dos fluidos existentes no local, fruto da disposição existente.

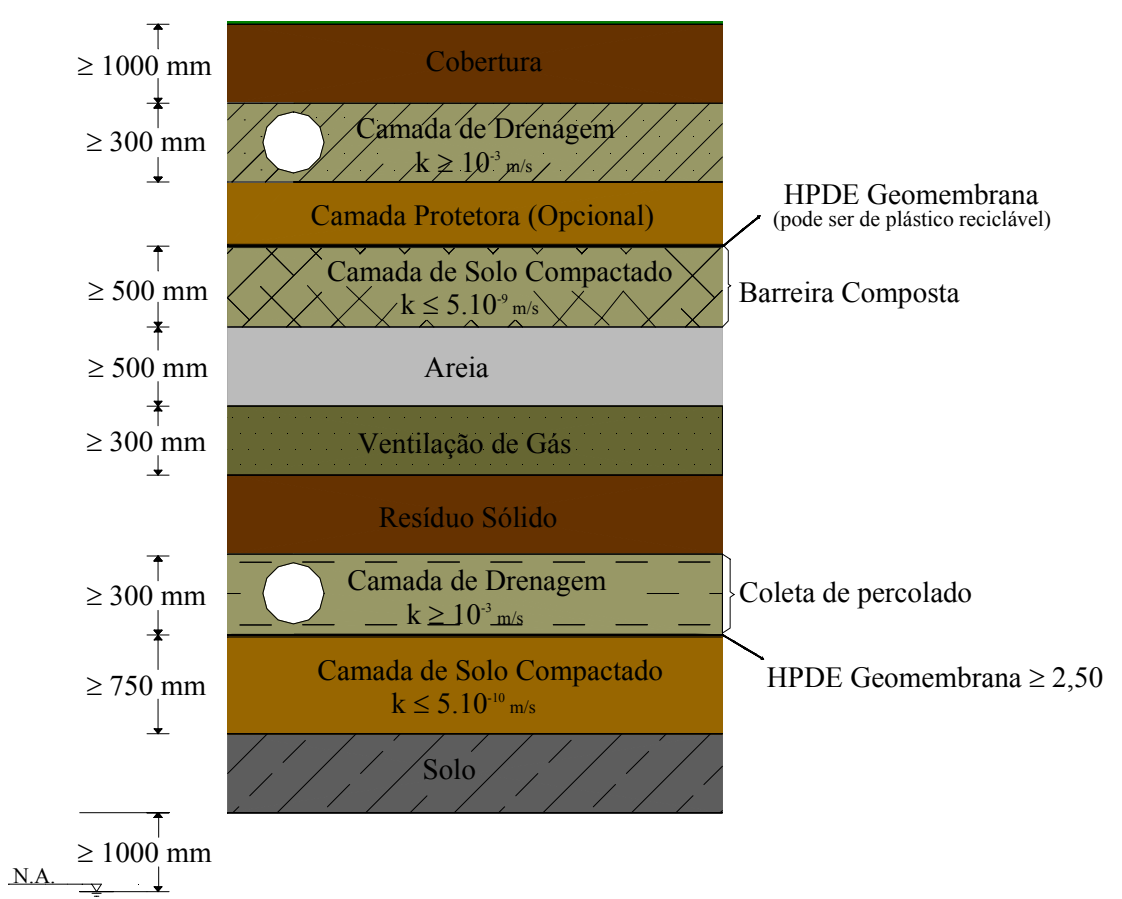

Figura 1: Base de aterro sanitário segundo a Norma Alemã, modificado Lima et. al. (2003).

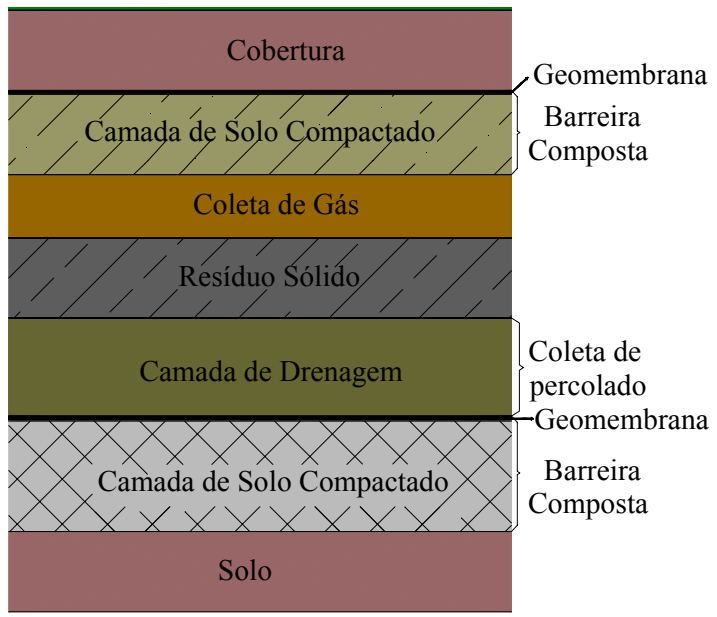

2a: Corte transversal - Legislação Federal

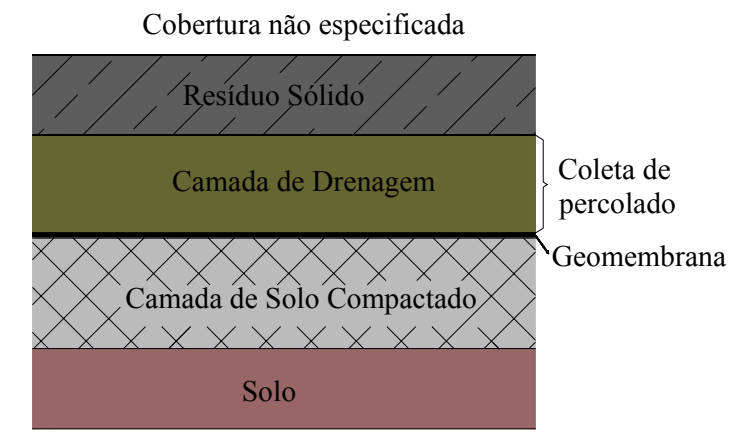

2b. Corte transversal - Legislação Paulista

Figura 2: Base de aterro Segundo recomendações da legislação Federal e do estado de São Paulo, modificado de Lima et. alii. (2003). 
Outros fatores de interesse são o $\mathrm{pH}$ do material e sua capacidade de troca catiônica (CTC), pois exercem influência na retenção de substâncias pela barreira. Para Jessberger (1995, apud BOFF e PARAGUASSU, 1999) para que uma barreira proporcione qualidade e segurança deve atender os requisitos listados na Tabela 1 .

\section{OBJETIVOS}

Tendo em vista as dificuldades técnicas enfrentadas pelo poder público municipal para atender às exigências legais quanto à construção de aterros sanitários e a disponibilidade, em grande parte do Estado de São Paulo, de solos de textura arenosa e média que, com tecnologia apropriada, podem ser utilizados para a construção de barreiras de proteção ambiental, foi desenvolvido este trabalho, cujos objetivos foram: (1) caracterizar o solo a ser testado para a construção de barreiras de proteção ambiental; (2) definir os procedimentos de estabilização química e de compactação mais apropriados para tal uso; (3) avaliar se tais materiais apresentavam a condutividade hidráulica esperada de uma barreira de proteção ambiental; e (4) propor uma seqüência de procedimentos que possa ser aplicada para situações similares.

\section{MATERIAL E MÉTODOS}

\subsection{ASPECTOS GERAIS}

O solo escolhido se desenvolveu sobre substrato da Formação Santo Anastácio (composta por arenitos arcoseanos finos a médios com lentes conglomeráticas de espessuras variadas) sendo descrito por IPT (1988) e IAC (1994) como Latossolo Vermelho Escuro, eutrófico a moderado, textura média e designado Unidade Estrela, e apresenta, em condições naturais, condutividade hidráulica média de $7,210^{-6} \mathrm{~m} / \mathrm{s}$.

O trabalho foi desenvolvido visando preparar corpos de prova de misturas de solo-cimento e solo-cal compactadas que apresentassem condutividade hidráulica compatível com seu uso como barreira, com o menor consumo de aditivo possível. Foram estudados diferentes teores de cimento e cal, sendo o material compactado submetido a ensaios de permeabilidade a carga variável considerando o tempo de vida das misturas sujeitas a duas condições de exposição (imersa e semi-imersa).

As misturas foram também sujeitas a ensaios de permeabilidade com área plena, como forma de avaliar sua condutividade hidráulica quando as 
mesmas fossem percoladas com água destilada, esgoto afluente (da entrada de uma lagoa de tratamento) e efluente (da saída da lagoa).

\subsection{CARACTERIZAÇÃO DO SOLO ESTUDADO}

Este conjunto de atividades correspondeu à realização de ensaios de caracterização do solo para a obtenção de informações a respeito de sua granulometria, textura, índices físicos e condições de compactação.

A primeira etapa consistiu da coleta de amostras de volume conhecido (com a cravação de cilindro cortante) para a obtenção dos índices físicos do solo em estudo no local de amostragem. Em seguida foram feitas as determinações da massa específica dos sólidos (MB-28) e dos limites de consistência (MB-30 e MB-31) de tal solo.

A etapa seguinte englobou a caracterização da granulometria do solo e suas condições de compactação, nas energias de compactação proctor normal e proctor modificado (norma MB-33).

Tabela 1: Condições para que um sistema de barreiras de proteção seja considerado adequado conforme Jessberger(1995 apud BOFF e PARAGUASSU, 1999).

\begin{tabular}{|c|c|c|}
\hline Requisitos & Propriedades inspecionadas & Influências Específicas do Local \\
\hline \multirow{10}{*}{ Impermeabilidade } & Permeabilidade & Gradiente hidráulico \\
\hline & \multirow{4}{*}{ Coeficiente de difusão } & $\begin{array}{l}\text { Quantidade de contaminante solúvel } \\
\text { (1) }\end{array}$ \\
\hline & & $\begin{array}{c}\text { Concentração de contaminante em } \\
\text { solução (2) }\end{array}$ \\
\hline & & Tipo de contaminante (3) \\
\hline & & Temperatura \\
\hline & \multirow{2}{*}{ Capacidade de retenção } & $(1),(2),(3)$ \\
\hline & & Tipo de argila \\
\hline & \multirow{3}{*}{$\begin{array}{c}\text { Sensibilidade do sistema a } \\
\text { imperfeições }\end{array}$} & Zona de alta permeabilidade \\
\hline & & Deformação ou ressecamento \\
\hline & & Cargas de soterramento \\
\hline \multirow{3}{*}{ Estabilidade } & \multirow{3}{*}{ Resistência ao cisalhamento } & Influências Mecânicas: \\
\hline & & Forças resultantes da deformação \\
\hline & & $\begin{array}{c}\text { Forças resultantes de cargas de } \\
\text { soterramento }\end{array}$ \\
\hline
\end{tabular}




\begin{tabular}{|c|c|c|}
\hline \multirow{1}{*}{ Resistência } & $\begin{array}{c}\text { Coesão (valores residual e } \\
\text { Não residual) }\end{array}$ & $\begin{array}{c}\text { Forças resultantes dos procedimentos } \\
\text { Construtivos }\end{array}$ \\
\cline { 2 - 3 } & Resistência à lixívia & $\begin{array}{c}\text { Influências Químicas: } \\
\text { tipo e composição da lixívia }\end{array}$ \\
\cline { 2 - 3 } & Resistência ao gás & $\begin{array}{c}\text { duração da exposição } \\
\text { Influências Térmicas }\end{array}$ \\
\cline { 2 - 3 } & Resistência à temperatura & Temperatura alta/baixa \\
\cline { 2 - 3 } & Resistência hidráulica & Influências Hidráulicas: \\
\cline { 2 - 3 } & Forças resultantes dos movimentos da \\
\cline { 2 - 3 } & Resistência à exposição & água \\
\cline { 2 - 3 } & clima e hidrogeologia do local \\
\hline
\end{tabular}

A distribuição granulométrica do solo mostra a predominância da fração areia, seguida da fração argila e pequena percentagem da fração silte (65\% de areia, $8 \%$ de silte e $27 \%$ de argila). A Tabela 2 apresenta os valores dos índices físicos e dos limites de consistência obtidos nos ensaios de caracterização do solo.

Com base nos resultados dos ensaios de caracterização, o solo estudado pôde ser classificado segundo os principais sistemas de classificação de solos para finalidades de engenharia, resultando as seguintes classificações: Classificação Textural - Areia Argilosa; Classificação Unificada - SC (Areia Argilosa); Classificação HRB - A-4 (arenoso pouco plástico); Classificação MCT - LA' (laterítico arenoso).

Tabela 2: Índices físicos e limites de consistência do solo utilizado.

\begin{tabular}{|c|c|c|c|c|c|c|c|c|}
\hline $\begin{array}{c}\rho \\
\left(\mathrm{g} / \mathrm{cm}^{3}\right)\end{array}$ & $\begin{array}{c}\mathrm{W} \\
(\%)\end{array}$ & $\begin{array}{c}\rho_{\mathrm{d}} \\
\left(\mathrm{g} / \mathrm{cm}^{3}\right)\end{array}$ & $\begin{array}{c}\rho_{\mathrm{s}} \\
\left(\mathrm{g} / \mathrm{cm}^{3}\right)\end{array}$ & $\mathrm{e}$ & $\begin{array}{c}\mathrm{Sr} \\
(\%)\end{array}$ & $\begin{array}{c}\mathrm{LL} \\
(\%)\end{array}$ & $\begin{array}{c}\text { LP } \\
(\%)\end{array}$ & $\begin{array}{c}\mathrm{IP} \\
(\%)\end{array}$ \\
\hline 1,69 & 12,98 & 1,50 & 2,72 & 0,81 & 43,58 & 26 & 17 & 9 \\
\hline
\end{tabular}

$\rho:$ massa específica do solo $\rho$ : massa específica dos sólidos LL - limite de liquidez w: teor de umidade e: índice de vazios $\rho d$ : massa específica aparente seca $\mathrm{Sr}$ - grau de saturação IP - índice de plasticidade

\subsection{DETERMINAÇÃO DAS CONDIÇÕES DE COMPACTAÇÃO}

Com relação aos teores de estabilizante testados (RIZZO, 2001 e RIBEIRO, 2002) foram realizados ensaios de compactação na energia 
proctor normal com três teores de estabilizante $(3,7$ e $10 \%$ de cimento e 4 , 8 e $12 \%$ de cal em massa). Os resultados mostraram que o ganho adicional de massa específica aparente seca com a energia modificada era pouco significativo, sendo mais apropriado o uso da energia proctor normal, que apresenta execução mais confiável no campo. Nas figuras 3 e 4 podem ser observadas as curvas de compactação obtidas para tais misturas na energia proctor normal.

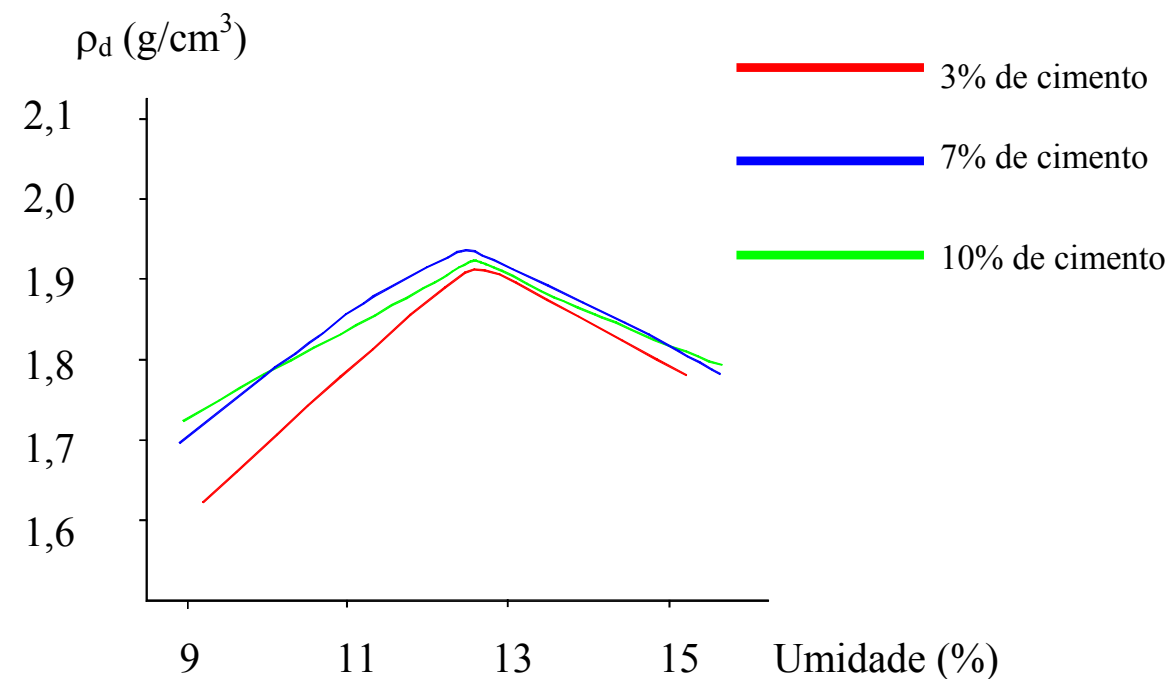

Figura 3: Curvas de compactação para as misturas solo-cimento.

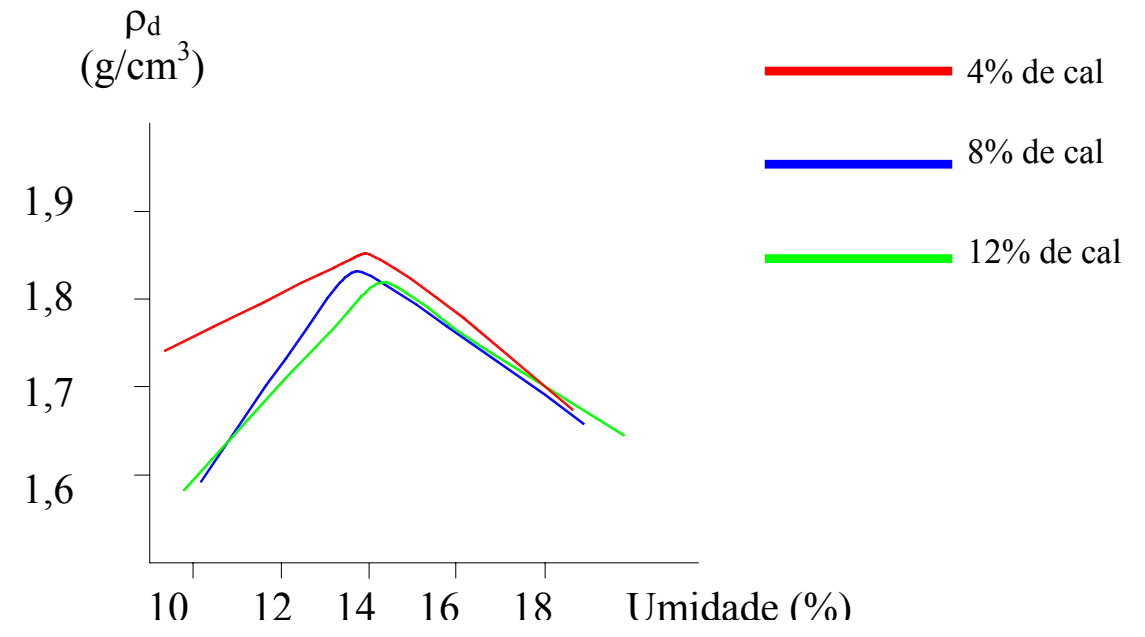

Figura 4: Curvas de Compactação para as misturas solo-cal.

Dos ensaios de compactação ilustrados nas figuras anteriores, foram obtidos os valores da massa específica aparente seca e da umidade ótima para cada um dos teores considerados, apresentados na Tabela 3. 
Tabela 3: Valores da massa específica aparente seca e da umidade ótima para teor.

\begin{tabular}{|c|c|c|}
\hline Teor/Estabilizante & $\mathrm{W}_{\text {ot }}(\%)$ & $\rho_{\mathrm{dmax}}\left(\mathrm{g} / \mathrm{cm}^{3}\right)$ \\
\hline $3 \%$ de cimento & 12,7 & 1,91 \\
\hline $7 \%$ de cimento & 12,5 & 1,92 \\
\hline $10 \%$ de cimento & 12,6 & 1,93 \\
\hline $4 \%$ de cal & 14,1 & 1,85 \\
\hline $8 \%$ de cal & 13,9 & 1,83 \\
\hline $12 \%$ de cal & 14,5 & 1,82 \\
\hline $\mathrm{W}_{\text {ot }}:$ umidade ótima & $\rho_{\text {dmax }}:$ massa específica aparente seca
\end{tabular}

Como se pode observar nas Figuras 3 e 4 e na Tabela 4, os resultados obtidos nos ensaios de compactação mostram que para as misturas solocimento o aumento no teor de cimento eleva a massa específica aparente seca sem modificar a umidade ótima enquanto para as misturas solo-cal o aumento do teor de cal na mistura reduz a massa específica aparente seca e aumenta a umidade ótima.

\subsection{ENSAIOS DE PERMEABILIDADE À CARGA VARIÁVEL}

Os corpos de prova utilizados nos ensaios de permeabilidade à carga variável foram compactados na energia proctor normal, no cilindro padronizado de ensaio, proporcionando corpos com $10 \mathrm{~cm}$ de diâmetro e $12,5 \mathrm{~cm}$ de altura, com 3,7 e $10 \%$ em massa de cimento e de 4,8 e $12 \%$ de cal em massa. Visando reproduzir condições de ensaio próximas das de campo, ao mesmo tempo em que se tentava uma redução eficiente de índice de vazios, optou-se por garantir um grau de compactação mínimo de $95 \%$ nas amostras compactadas.

Os corpos de prova assim moldados foram guardados em câmara úmida dentro de bandejas metálicas em duas diferentes situações: semiimersos (bandeja com água até uma atura equivalente à metade da altura do corpo de prova) e imersos (bandeja com água até a altura do corpo de prova), representando uma tentativa de simulação das condições ambientais sob as quais as camadas possam vir desempenhar na prática, ou seja, a situação de semi-imersos simulou a condição de início de saturação do material numa possível aplicação como base de aterro sanitário (logo após sua construção e início da deposição dos resíduos sobre o mesmo) enquanto 
que a situação fez uma simulação da situação na qual a camada esteja toda saturada.

Com o objetivo de avaliar o efeito do contato dos corpos de prova com a água em função do tempo, foram considerados três intervalos de tempo de exposição $(120,180$, e 240 dias) anteriormente à realização dos ensaios para determinação de sua condutividade hidráulica.

\subsection{ENSAIOS DE PERMEABILIDADE EM ÁREA PLENA}

O uso de corpos de prova em formato miniatura (técnica inédita), representa uma nova possibilidade de avaliação do comportamento destas misturas por meio de ensaios de permeabilidade "com área plena", possibilitando maior agilidade e menores custos no processo.

A compactação dos corpos de prova miniatura $(5 \mathrm{~cm}$ de altura por $5 \mathrm{~cm}$ de diâmetro) foi feita estaticamente no interior de tubos de PVC de $13 \mathrm{~cm}$ de altura por $5 \mathrm{~cm}$ de diâmetro com a energia do ensaio proctor normal, em 2 (duas) camadas de $2,5 \mathrm{~cm}$ cada, com $7 \%$ de cimento em massa para os corpos de prova solo-cimento e $8 \%$ de cal em massa para as misturas solo-cal.

Tais teores foram adotados, pois os resultados dos ensaios de permeabilidade a carga variável mostravam que com esses teores se obtinha boa redução da condutividade hidráulica com o menor consumo possível de estabilizante. Também nesse caso, o grau de compactação mínimo dos corpos de prova foi de $95 \%$.

Os corpos de prova assim moldados foram então colocados em contato com três diferentes fluidos percoladores: água destilada, esgoto afluente e esgoto efluente de lagoa de estabilização. A Figura 5 mostra o ensaio de permeabilidade em área plena já montado.

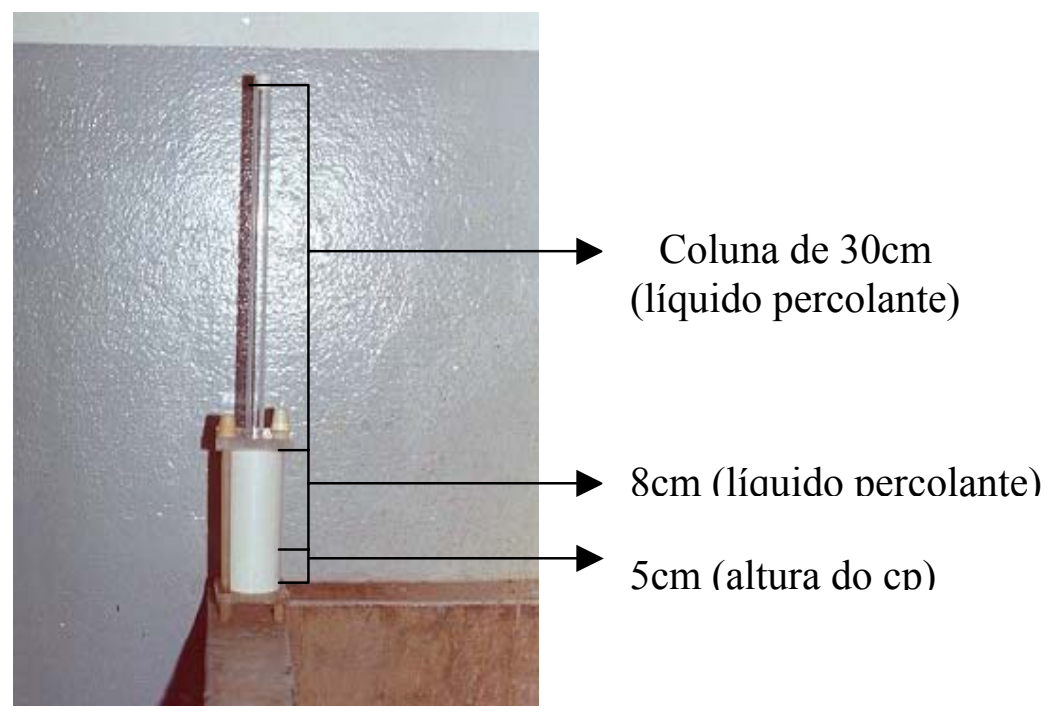

Figura 5: Ensaios de permeabilidade em área-plena. 
A fim de se avaliar o efeito do fluido de percolação sobre a estabilidade das misturas compactadas foram conduzidos os ensaios de permeabilidade com área plena, considerando três diferentes situações: misturas sujeitas à percolação de água destilada, esgoto afluente da lagoa (para a avaliar as condições de percolação no trecho inicial da lagoa) e esgoto efluente da lagoa (condições de percolação no trecho final).

Concluída a fase de saturação dos corpos de prova, foram efetuadas leituras nos dispositivos durante 90 dias para que verificasse, dentro do prazo possível no presente projeto, variações nos coeficientes de permeabilidade dos corpos de prova com o tempo.

No princípio eram efetuadas leituras diárias, após algum tempo, como se verificou que o coeficiente de permeabilidade das amostras percoladas com água e com água residuária não sofriam variações, as leituras passaram a ser efetuadas semanalmente e quinzenalmente.

\section{RESULTADOS}

\subsection{ENSAIOS DE PERMEABILIDADE À CARGA VARIÁVEL}

A Tabela 4 mostra as médias dos valores de condutividade hidráulica (médias de cinco amostras) apresentadas pelos corpos de prova submetidos a ensaios de permeabilidade à carga variável. Os resultados obtidos mostram valores de condutividade hidráulica compatíveis com o uso das misturas compactadas como barreiras de proteção ambiental.

\subsection{ENSAIOS DE PERMEABILIDADE EM ÁREA PLENA}

A Tabela 5 apresenta os valores de permeabilidade em área plena. Neste caso, os resultados apresentados também indicam condutividade hidráulica compatível com o uso dos materiais como barreiras, com o benefício adicional que tendo o esgoto como fluido de percolação a condutividade hidráulica tende a ficar ainda menor. 
Tabela 4: Permeabilidade das misturas solo-cimento e solo cal.

\begin{tabular}{|c|c|c|c|c|c|c|c|}
\hline Condição & Tempo & \% Cimento & $\mathrm{k}(\mathrm{m} / \mathrm{s})$ & Condição & Tempo & \% Cal & $\mathrm{k}(\mathrm{m} / \mathrm{s})$ \\
\hline semi-imersa & 120 & 3 & $1,4710^{-8}$ & semi-imersa & 120 & 4 & $6,1210^{-10}$ \\
\hline semi-imersa & 120 & 7 & $8,3710^{-10}$ & semi-imersa & 120 & 8 & $7,5110^{-10}$ \\
\hline semi-imersa & 120 & 10 & $9,4610^{-10}$ & semi-imersa & 120 & 12 & $4,1810^{-10}$ \\
\hline semi-imersa & 180 & 3 & $3,4410^{-9}$ & semi-imersa & 180 & 4 & $5,2910^{-10}$ \\
\hline semi-imersa & 180 & 7 & $3,4610^{-10}$ & semi-imersa & 180 & 8 & $4,6810^{-10}$ \\
\hline semi-imersa & 180 & 10 & $4,1110^{-10}$ & semi-imersa & 180 & 12 & $2,6410^{-10}$ \\
\hline semi-imersa & 240 & 3 & $6,3310^{-10}$ & semi-imersa & 240 & 4 & $8,5610^{-10}$ \\
\hline semi-imersa & 240 & 7 & $6,3310^{-10}$ & semi-imersa & 240 & 8 & $6,1710^{-10}$ \\
\hline semi-imersa & 240 & 10 & $3,7110^{-10}$ & semi-imersa & 240 & 12 & $3,2810^{-10}$ \\
\hline imersa & 120 & 3 & $3,9410^{-9}$ & Imersa & 120 & 4 & $4,2510^{-9}$ \\
\hline imersa & 120 & 7 & $4,2210^{-10}$ & Imersa & 120 & 8 & $7,7710^{-9}$ \\
\hline imersa & 120 & 10 & $2,3510^{-9}$ & imersa & 120 & 12 & $1,1610^{-9}$ \\
\hline imersa & 180 & 3 & $2,0010^{-9}$ & imersa & 180 & 4 & $2,9210^{-9}$ \\
\hline imersa & 180 & 7 & $2,9710^{-10}$ & imersa & 180 & 8 & $3,7810^{-10}$ \\
\hline imersa & 180 & 10 & $8,6310^{-10}$ & imersa & 180 & 12 & $3,6710^{-10}$ \\
\hline imersa & 240 & 3 & $7,4210^{-10}$ & imersa & 240 & 4 & $3,1210^{-9}$ \\
\hline imersa & 240 & 7 & $4,3710^{-10}$ & imersa & 240 & 8 & $4,1510^{-10}$ \\
\hline imersa & 240 & 10 & $2,1810^{-10}$ & imersa & 240 & 12 & $3,3910^{-10}$ \\
\hline
\end{tabular}

Tabela 5: Permeabilidade Área Plena.

\begin{tabular}{|c|c|c|}
\hline ESTABILIZANTE & PERCOLANTE & $\mathrm{k}(\mathrm{m} / \mathrm{s})$ \\
\hline $7 \%$ Cimento & Água destilada & $5,1910^{-10}$ \\
\hline $8 \%$ Cal & Água destilada & $6,5710^{-10}$ \\
\hline $7 \%$ Cimento & Esgoto afluente & $1,0310^{-11}$ \\
\hline $8 \%$ Cal & Esgoto afluente & $1,2410^{-11}$ \\
\hline $7 \%$ Cimento & Esgoto efluente & $1,2010^{-11}$ \\
\hline $8 \%$ Cal & Esgoto efluente & $1,2410^{-11}$ \\
\hline
\end{tabular}




\section{DISCUSSÃo}

O principal requisito de natureza hidráulica exigido para uso como barreira de proteção ambiental foi atendido pelos materiais testados, pois quase todos apresentaram valores de condutividade hidráulica da ordem de $10^{-9} \mathrm{~m} / \mathrm{s}$ ou menores, cabendo analisar a influência dos fatores envolvidos (tipo de estabilizante, teor de estabilizante, tempo de cura e condição de cura).

Quanto aos tipos de estabilizante testados (cal e cimento) os resultados mostram valores de condutividade hidráulica da mesma ordem de grandeza para os dois estabilizantes utilizados.

Com relação ao teor de estabilizante se verifica redução significativa de condutividade hidráulica até os teores de $7 \%$ de cimento e $8 \%$ de cal em massa. Para valores acima destes $(10 \%$ de cimento e $12 \%$ de cal $)$ a redução da condutividade hidráulica é pouco representativa.

Para o fator tempo de cura, os resultados mostram uma tendência de redução da condutividade hidráulica até os 180 dias de cura, não havendo variação significativa após isso.

A condição de cura a qual os materiais foram submetidos (imersa ou semi-imersa) não mostrou influência significativa nos valores obtidos, quase não havendo diferença entre os resultados obtidos para as amostras sujeitas à condição imersa e à condição semi-imersa.

Embora usando proposta sem similar na literatura brasileira, os resultados obtidos são tão promissores quanto aqueles encontrados por outros grupos brasileiros que tem pesquisado o assunto, tal como Boscov et. al. (1999), com barreiras de solos argilosos, Ritter, et. al. (1999), com barreiras compostas por misturas de argilas, e Boff e Paraguassu (1999), com barreiras produzidas com misturas de solo argiloso e arenoso.

Com base no exposto se verifica que misturas preparadas com solo laterítico arenoso e cal ou cimento, quando compactadas, podem proporcionar materiais com valores de condutividade hidráulica apropriados a seu como barreira de proteção ambiental. A seqüência de procedimentos necessária para que se atinja tal benefício pode ser resumida como segue.

\section{ROTINA DE APLICAÇÃO DA TÉCNICA}

Verificado o fato que as misturas estudadas atendem aos requisitos, foi proposta uma rotina da aplicação da técnica, para padronizar procedimentos para uso desse tipo de solução em obras que se utilizem solos com características similares ao utilizado no presente trabalho. 


\subsection{TIPO DE SOLO}

Os levantamentos visando avaliar as condições do solo a ser utilizado devem contemplar os ensaios de caracterização (mineralogia, índices físicos, granulometria e limites de consistência). O solo deve apresentar textura arenosa e uma fração argilosa de pelo menos $20 \%$, não conter minerais potencialmente expansivos e possuir baixa plasticidade (IP < $15 \%)$.

\subsection{CONDIÇÕES DE COMPACTAÇÃO}

Os ensaios de compactação devem ser conduzidos considerando não só a possível redução na permeabilidade do solo e da mistura compactada, mas também a viabilidade do emprego de tal energia de compactação na obra em questão.

\subsection{EXPERIMENTOS}

Com o solo que atenda aos requisitos do tópico 6.1 poderão ser realizados ensaios de permeabilidade com carga variável em menor quantidade, englobando apenas um teor de um dos aditivos considerados, como forma de controle do desempenho da mistura compactada.

Da mesma forma, deve-se proceder a um rígido controle da compactação, tanto em laboratório (na moldagem dos corpos de prova) como no campo (na execução da barreira) para que se possa ter confiança no desempenho do material.

É interessante ainda que sejam efetuados ensaios de permeabilidade com área plena com o fluido a ser efetivamente posto em contato com a barreira nas condições de operação do empreendimento.

\section{CONCLUSÕES}

As análises dos resultados obtidos permitem as seguintes conclusões:

- a adição de cal ou cimento promove a redução da condutividade hidráulica das misturas compactadas, tornando o material estudado apto a ser usado como barreira de proteção ambiental;

- teores de 7\% de cimento e $8 \%$ de cal em massa são suficientes para os resultados pretendidos;

- não há redução significativa da permeabilidade após 180 dias de cura da mistura, indicando que o processo de estabilização do material já deve ter se completado após esse tempo; 
- a condição de exposição não interfere no desempenho da condutividade hidráulica;

- as misturas responderam muito bem quando submetidas à percolação de esgoto afluente e efluente;

- os materiais produzidos com solo-cimento na porcentagem de 7\% mostraram menor condutividade hidráulica que a mistura solo-cal a $8 \%$;

- a construção de barreiras de proteção ambiental com solo laterítico arenoso estabilizado quimicamente é solução tecnologicamente viável e de baixo custo para o uso em questão

- os ensaios de permeabilidade com área plena podem ser de grande utilidade, pois mostram resultados iguais aos do ensaio a carga variável com menores custos e tempo de execução.

\section{AGRADECIMENTOS}

Os autores agradecem à FAPESP o apoio para o desenvolvimento das pesquisas, na forma dos Processos 01/11217-3 e 02/02455-0.

\section{REFERÊNCIAS}

BOFF, F.E.; PARAGUASSU, A.B. Avaliação da titulação potenciométrica na avaliação das possibilidades de uso de solos lateríticos como liners. In: Congresso Brasileiro de Geotecnia Ambiental, 4, 1999, São José dos Campos. Anais..., Associação Brasileira de Mecânica dos Solos, São José dos Campos, p. 362-366, 1999.

BOSCOV, M.E.G.; OLIVEIRA, E.; GHILARDI, M.P. \& SILVA, M.M. Difusão de metais através de uma argila laterítica compactada. In: Congresso Brasileiro de Geotecnia Ambiental, 4, 1999, São José dos Campos. Anais..., Associação Brasileira de Mecânica dos Solos, São José dos Campos, 323-330Pp., 1999.

INSTITUTO AGRONÔMICO DA CAMPINAS (IAC). Levantamento pedológico semidetalhado de alguns municípios da região de influência do Conjunto Hidrelétrico de Urubupungá - Estado de São Paulo. São Paulo, escala 1:100.000, 1994.

INSTITUTO DE PESQUISA TECNOLÓGICAS (IPT). Levantamento pedológico da área do Cinturão verde da cidade de Ilha Solteira SP. São Paulo, , escala 1:6.000, 1988.

LEITE, A.L.L. A difusão molecular do $\mathrm{K}^{+}$e $\mathrm{Cl}^{-}$em solos naturais compactados: uma perspectiva para uso em liners. São Carlos: EESC/USP. Dissertação (Mestrado em Geotecnia) - Escola de 
Engenharia de São Carlos, Universidade de São Paulo, 1997.

LEITE, J.C. Estudos laboratoriais de percolação em colunas de misturas de solos lateríticos compactadas: Equipamentos e ensaios. São Carlos: EESC/USP. Tese (Doutorado) - Escola de Engenharia de São Carlos, Universidade de São Paulo, 2000.

LIMA, D.C., SILVA, C.H.C., BARBOSA, P.S.A., CARVALHO, C.A.B.; TRINDADE, T.P. Municipal solid waste landfill and cover regulations. Universidade Federal de Viçosa - Viçosa, Minas Gerais, 2003.

RIBEIRO, R.A.V. Avaliação do desempenho hidráulico de barreiras de proteção ambiental produzidas com solo laterítico arenoso compactado estabilizado quimicamente. Ilha Solteira: FEIS/UNESP. Dissertação (Mestrado) - Faculdade de Engenharia de Ilha Solteira, Universidade Estadual Paulista, 2002.

RITTER, E., EHRLICH, M.; BARBOSA, M.C. Difusão e sorção de soluções múltiplas e monossoluções em solos argilosos salinos e não salinos. In: CONGRESSO BRASILEIRO DE GEOTECNIA AMBIENTAL, 4, 1999, São José dos Campos. Anais..., Associação Brasileira de Mecânica dos Solos, São José dos Campos, 331-338p., 1999.

RIZZO, R.P. Avaliação da condutividade hidráulica em solo laterítico arenoso compactado estabilizado com cimento para uso como liner. Faculdade de Engenharia de Ilha Solteira (UNESP), 27p., 2001. (Relatório de pesquisa encaminhado à Fapesp). 